\title{
EFFECTS OF DANCE AND MUSIC THERAPY
}

\author{
Dr. Saroj Kothari \\ Professor \& Head, Department of Psychology \\ Govt. M.L.B.P.G. Girls College, Indore
}

Arts have consistently been part of life as well as healing throughout the history of humankind. Today, expressive therapies have an increasingly recognized role in mental health, rehabilitation and medicine. The expressive therapies are defined as the use of art, music, dance/movement drama, poetry/creative writing, play and sand play within the context of psychotherapy, counseling, rehabilitation or health care.

Through the centuries, the healing nature of these expressive therapies has been primarily reported in anecdotes that describe a way of restoring wholeness to a person struggling with either mind or body illness. The Egyptians are reported to have encouraged people with mental illness to engage in artistic activity (Fleshman \& Fryrear, 1981); the Greeks used drama and music for its reparative properties (Gladding, 1992); and the story of King Saul in the Bible describes music's calming attributes. Later, in Europe during the Renaissance, English physician and writer Robert Burton theorized that imagination played a role in health and well-being, while Italian philosopher de feltre proposed that dance and Play was central to children's healthy growth and development (Coughlin, 1990).

The idea of using the arts as an adjunct to medical treatment emerged in the period from the late 1800 s to the 1900 s alongside the advent of psychiatry. For example, documented uses of music as therapy can be found following World War I when "miracle cures" were reported, resulting form reaching patients through music when they responded to nothing else. The creative arts therapies became more widely known during the 1930s and 1940s when psychotherapists and artists began to realize that self-expressions through nonverbal methods such as painting, music making, or movement/dance might be helpful for people with severe mental illness.

Over the last several decades, play therapy and sand play therapy have also become part of expressive therapies practice. Music and imagery therapies are now used routinely with hospitalized patients for pain reduction, relaxation, and childbirth; art and play are proving to be essential in trauma debriefing, resolution, and recovery with children (Malchiodi, 2001) and writing is prescribed to ameliorate symptoms of illnesses such as asthma and arthritis as well as to decrease posttraumatic stress in individuals who have experienced crisis or loss (Pennebaker, 1997).

\section{DANCE THERAPY:-}

The American Dance Therapy Association (ADTA), founded in 1966 by 76 charters members, is the psychotherapeutic use of movement as a process that furthers the emotional, cognitive, social and physical integration of the individual (ADTA, 2003). Dance/movement therapy uses 


\section{INTERNATIONAL JOURNAL Of RESEARCH -GRANTHAALAYAH \\ A knowledge Repository}

Art

movement and the body combined with skills of psychotherapy, counseling, and rehabilitation to help people with different needs. The importance of the body in treating mental disorders also colored the development of dance/movement therapy (Chodorow, 1991; Schmais, 1980).

The Handbook of inquiry in the Arts Therapies reviews the relationship between research and practice in the arts and covers dance and movement therapy studies from 1940-1990 (Payne, 1993). An annotated bibliography includes clinical, theoretical and other research material in the field of dance/movement therapy. The information covers adolescent discarders, anxiety, childhood illnesses, eating disorders, family, geriatrics, mood disorders, neuroses, personality disorders, physical and sexual abuse, schizophrenia, somatic disorders, substance abuse, and traumatic brain injury (Fledderjohn \& Sewickley, 1993).

\section{DEPRESSION:-}

Dancing has the power to change the way people feel. There is a growing body of evidence which shows that dancing can improve the mood of people with both mild and severe depression. Symptoms of depression and anxiety decreased and work productivity increased by dance/movement therapy (Reinemann, 1999). Dancing1ed to a reduction in feelings of depression, anxiety and hostility (Jeong, 2005). 30 minutes session of dance was enough to reduce depressive symptoms and increase feelings of vitality; in depressive patients (Koch, 2007).

\section{SCHIZOPHRENIA:-}

Patients may be able to express in movement feelings that they cannot put into words (Ellis, 2001). Movement therapy may be a venue for tapping into a child client's inner world (Nagpal \& Ruta, 1997).

\section{MIND PSYCHE:-}

Using winnicott's concept of mind psyche, a discussion among the members and leader of a dance therapy group discusses why certain moments in the dance experience feel simultaneously frightening and exciting. Mind psyche means a state which the soma has been drawn into the mind, which, in turn prevents the person of the natural mutual interrelation between psyche and soma (Lavender, 1992).

\section{DEFICITS OF SELF:-}

Deficits of self include disorders such as schizophrenia, narcissism, and schizoid and paranoid illnesses. Dance therapy is one of the creative arts therapies used to help a patient organize or synthesize affective issues that include abandonment, rage, sexual trauma, loss, grief and pain (Robbins, 1998).

\section{CEREBRAL VASCULAR ACCIDENT:-}

Dance/movement therapy enhanced physical, psychological, and cognitive functioning of those people who suffered form traumatic brain injury. (Berrol, Ooi \& Katz, 1997). 


\section{INTERNATIONAL JOURNAL Of RESEARCH -GRANTHAALAYAH

Art

\section{ANXIETY:-}

A meta-analysis published in 1996 suggests dance/movement therapy may help children, psychiatric patients and elderly parsons with varying disorders, anxiety in particular. It appears that adults and adolescents benefit more from dance/movement therapy than children (Ritter \& Low, 1996).

\section{DANCE AND THINKING:-}

In 1990 Madonna a song called 'Vogue' who's opening line is 'Strike a pose'. The basic premise of the song is that if you want to escape the pain of life and be something else, something better, then you should lose yourself on the dance floor the idea being that striking a pose can help you unlock your imagination. Carney et. al. (2010) researchers at Columbia and Harvard universities found that not only does striking a pose change the way people think, it also changes people in a physiological level too. Those people who had been standing or sitting in 'high-power poses' said that they felt more powerful and more in charge, took the high-risk bet, and their testosterone (sex hormone level went up and their cortisol (stress hormone) level went down.

\section{PROBLEM SOLVING:-}

Dancing can increase in scores on divergent thinking (multiple correct answers to a given problem) tasks but there were no change in convergent thinking (just one correct answer) task.

\section{DANCE AND GENERTICS:-}

William M.Brown (2005) asked teenagers to dance freestyle in a laboratory. They then measured the size of everyone's ears, fingers, wrists, elbows, ankles, feet and knees. They were interested in the relative size of the each body part on the left and the right side of the body. With this information they were able to calculate how physically symmetrical each person was. They found that the dancing of more symmetrical people was rated as better than the dancing of less symmetrical people. Physical symmetry is an indicator of genetic quality and that physically symmetrical people are better quality specimens than physically asymmetric people.

\section{ENHANCE HEALING CAPACITY:-}

Dance/movement therapy may positively affect body image. It may also promote the creative process and enhance healing capacity with activities such as exploring tension and relaxation through movement, and connecting these movements to certain times in life. In addition, dance/movement therapy can enhance self-awareness, including the ability to sense and feel emotions and other sensations such as hunger, satiety, tension and relaxation (DuBose, 2001) Movement may also be a way to restore the dialog between the mind and the body and create a balance between them (De Tommasi, 1999).

\section{MOTOR DEVELOPMENT IN CHILDREN:-}

Imagery and improvisation may be useful in helping school children strengthen bond between creativity and motor development. Movement education helps normal and mentally handicapped children develop creative and self expression and positive body image (Magruder, 1981). 


\section{INTERNATIONAL JOURNAL Of RESEARCH -GRANTHAALAYAH

Particularly useful when verbal communication is blocked, dance therapy can channel tension toward bodily integration, appropriate affect, insight into behavior, and improved social interaction because it combines principles from bioenergetics and Gestalt therapy while emphasizing body activity (Kavaler, 1977).

\section{RANGE OF MOTION:-}

Occupational therapy is an important intervention for elderly people because it promotes active and productive lifestyles. Inactivity is one leading cause of morbidity and mortality among older persons. Occupation therapy programs for older people include dance/movement therapy interventions (Valentine et.al., 1992). Dance/movement therapy has been used to increase range of motion in elderly persons. Scott (2001) found that dance/movement therapy has been useful in improving cognitive functioning of older adults who have sustained neurotraumatic injuries.

\section{SEXUAL ABUSE:-}

Dance therapy has been used to deal with problems of self concept and symptoms of shame and trauma in sexually abused adolescent girls living in an institution Truppi, 2001). In young children sexual abuse may result in distorted body image, dissociative disorders, low self esteem, behavioral problems, eating disorders, and self mutilation. These six variables may be addressed in dance therapy interventions.

\section{MUSIC THERAPY:-}

Music and Medicine have been partners from the beginning of western medical practice Ancient physicians such as Hippocrates and Galen upheld strongly the idea of treating the whole person rather than addressing discrete symptoms. Music therapy, as the term is used today, developed during World War II overcrowded conditions in military hospitals provided an impetus for inviting adjunctive therapies into these facilities (Pratt, 1985). The National Association for Music Therapy (NAMT) was organized in 1950 to standardize training and promote unity among those who were already involved as volunteers and specialists using music with patients, particularly in hospitals with convalescent veterans (Schneider, 1985). Both the NAMT and the American Association for Music Therapy (AAMT) which was organized in 1971 were brought together with the creation in 1998 of the American Music Therapy Association (AMTA), whose purpose is the development of the therapeutic use of music in rehabilitation, special education and community settings. Music therapy uses music to effect positive changes in the psychological, physical, cognitive, or social functioning of individuals with health or educational problems (American Music Therapy Association, 2004).

\section{BRAIN INJURIES:-}

Music therapy help children with severe traumatic brain injuries emerge faster from a coma and than orientate. Outcome measures in this study showed changes in heart followed by orienting to sounds and vocalizations and, later, singing songs, which then preceded speech recovery (Rosenfeld, 1999). Music therapy may improve mood and social interactions among patients who have sustained acute traumatic brain injury and stroke (Nayak \& Wheeler, 2000). Music 


\section{INTERNATIONAL JOURNAL Of RESEARCH -GRANTHAALAYAH

may also be the ideal domain for exploring the brain's ability to perform complex cognitive tasls (Knox \& Jutai, 1996).

\section{ATTENTION DEFICIT DISORDER:-}

The Music Medicine Study showed that $70 \%$ of children who have attention deficit disorder and who received neuro feedback training with selected background music (instrumental music by Mozart) significantly reduced targeted behaviors such as inattention, impulsivity and social skills when compared with children who had the neurofeedback training alone. (Pratt et.al. 1995).

\section{BIOFEEDBACK AND MUSIC:-}

Biofeedback training may be enhanced by the use of selected music. Effects on the autonomic system through combined psychometric immunology techniques and music can affect such measures as heart rate, blood pressure, and stress hormone production (Sedei et.al. 1987).

\section{PAIN MANAGEMENT:-}

Music played throughout the post anesthesia care stage may positively affect the pain experience and improve patient comfort during surgery (Shertzer, 2001). Patients are advised upon admission that surgical patients who listen to music during their time in the hospital are more relaxed, experience less pain, and are not bothered by unfamiliar noises around them. (Pratt, 1999). Music therapy has been used as a successful destructor with burn patients (Presner et.al.2001).

\section{MUSCULOSKELETAL INJURIES:-}

Rhythmic auditory stimulation may be used as an entrainment and therapy technique for positive effects on the gait of stroke patients as well as patients who have Parkinson's disease (Mclntosh, et.al.1996). Distraction techniques, including music, are an effective adjunct to analgesia for children who have musculoskeletal pain in an emergency department setting (Tanabe et.al. 2002).

\section{PEDIATRICS:-}

Music therapy can decrease anxiety in children who have cancer. The music therapist may actually accompany the child to treatments to teach relaxation strategies that help the patient cope better with stress and pain (Good et.al.2001).

Johnson (1985) observes that expressive therapists "have a powerful vision, and we have emerged for a reason". In the same vein, the expressive therapies as a force with psychology and counseling have emerged for a reason. Creativity in therapy has the potential to impact clients in memorable ways, expressive therapies stimulate the senses, thereby "sensitizing" individuals to untapped aspects of themselves and thus facilitating self-discovery, change and reparation (Gladding, 1991).

Life is not a bed of roses so one must learn to dance to the tune of life. Only that will make life worth living. 


\section{INTERNATIONAL JOURNAL Of RESEARCH -GRANTHAALAYAH \\ A knowledge Repository}

Art

Ever wondered why music has a healing property. There seems to be an intense relationship between music and mind. Even before the baby is out in the world-a connection exists between music and brain. In other words the relationship dates back to before birth.

Dance and Music therapies are an important part of modern health care. It is hoped that the research in these therapies will one day be commensurate with the successful clinical applications in hospitals, institutions, and private practice.

\section{REFERENCES}

1 American Dance Therapy Association. http://www.adta.org. Accessed August 23,2003

2 American Music Therapy Association. Definition of music therapy [Online]. 2004; Available at www. musictherapy.org.

3 Berrol CF, Ooi WL, Katz SS. Dance/movement therapy with older adults who have sustained neurological insult: a demonstration project. The American Journal of Dance Therapy 1997;19(2):135-60.

4 Brown, W.M., Cronk, L., Crochow, K., Jacobson, A., Lui, C.K. and Popovic, Z., 'Dance reveals symmetry especially in young men', Nature, 2005; Vol. 402, pp.877-879.

5 Camey D.R., Cuddy, A.J.C. and Yap, A.J. 'Power posig:btief non-verbal displays affect neuroendocrine levels and risk tolerance', Psychological Science, 2010; Vol. 21, No. 10, pp. 1363-1368.

6 Chodorow J, Dance therapy and depth psychology: the moving imagination. London: Routledge; 1991.

7 Coughlin, E. Renewed appreciation of connections between mind and body stimulate researchers to harness the healing power of the arts. Chronicles of Higher Education, 1990; 36, 9.

8 De Tommasi V. Dance-movement-therapy (DMT) and eating disorders: a psssible method of approach, Methods of Research \& Clinical Experience 1999; 6 (1-2):129-45.

9 DuBose LR. Dance/movement treatment perspectives. In: Robert-McComb JJ, editor. Eating disorders in women and children: prevention, stress management, and treatment. Boca-Raton (FL): CRC Press; 2001; P. 373-85.

10 Ellis R. Movement metaphor as mediator: a model for the dance/movement therapy: Process. Arts in Psychotherapy 2001; 28(3): 181-90.

11 Fledderjohn H, Sewickley J. An annotated bibliography of dance/movement therapy: 1940-1990. Columbia (MD): American Dance Therapy Association; 1993.

12 Fleshman, B., \& Fryrear, J. The arts in therapy. Chicago: Nelson-Hall; 1981.

13 Gladding, S. counseling as an art: The creative arts in counseling. Alexandria, VA: American Counseling Association; 1992.

14 Good M, Stanton-Hicks M, Grass JA, Anderson GC, Lai HL, Roykulcharoen V, et al. Relaxation and music to reduce postsurgical pain. J Adv Nurs 2001; 33 (2): 208-15. 


\section{INTERNATIONAL JOURNAL Of RESEARCH -GRANTHAALAYAH

15 Jeong, Y.J., Hong, S.C., Lee, M.S., Park, M-C., Kim, Y.K. and Sub, C-M. 'Dancel movement therapy improves emotional responses and modulates neurohormones in adolescents with mild depression', International Journal of Neuroscience, 2005; Vol. 115, No. 12, pp. 1711-1720.

16 Johnson, D.R. Envisioning the link among the creative arts therapies. Arts in Psychotherapy, 1985; 12(4), 233-238.

17 Kavaler S. Dance therapy. Transcranial Mental Health Research Newsletter 1977; 19 (1): 2-5.

18 Knox R, Jutai J. Music-based rehabilitation of attention following brain injury. Canadian Journal of Rehabilitation 1996; 9(3):169-81.

19 Koch, S.C., Morlinghaus, K. and Fuchs, T. 'the joy dance: specific effects of a single dance intervention on psychiatric patients with depression', The Arts in Psychotherapy, 2007; Vol. 34, pp.340-349.

20 Lavender J. Winnicott's mind psyche and its treatment. The American Journal of Dance Therapy 1992; 14 (1): 31-9.

21 Magruder E. Imagery and improvisation in dance in the schools. Journal of Physical Education and Recreation 1981; 52(3): 76-8.

22 Malchiodi, C.A.Using drawings as interventions with traumatized children. Trauma and Loss: Research and Interventions, 2001; 1(1), 21-27.

23 Mates M. Altered levels of consciousness in schizophrenia. Journal of Orthomolecular Medicine 1992; 7(4):216-20.

24 McIntosh GC, Thaut MH, Rice RR. Rhythmic auditory stimulation as an entrainment and therapy techmique: effects on gait of stroke and Parkinson's patients. In Pratt RR, Spintge R. editors. Music Medicine 2. St. Louis (MO): MMB Music, 1996; p.145-52.

25 Nagpal M, Ruta A.M. Joy in schizophrenia through dance/movement therapy. American Journal of California Alliance for Mental Illness 1997; 8(3):53-5.

26 Nayak S, Wheeler BL, Shiflett SC, Agostinielli S. Effect of music therapy on mood and social interaction among individuals with acute traumatic brain injury and stroke Rehabilitation Psychology 2000; 45(3):274-83.

27 Payne H, editor. Hondbook of inquiry in the arts therapies; one river, many currents. Bristol (PA): Jessica Kingsley; 1993.

28 Pratt RR. The historical relationship between music and medicine. In: Pratt RR, editor. The $3^{\text {rd }}$ international Symposium on Music in Medicine, Education, and Therapy for the Handicapped. Lanham (MD): University Press of America; 1985; P. 237-69.

29 Pratt RR, Abel H-H, Skidmore J. The effects of neurofeedback with background music on EEG patterns of ADD and ADHD children. International Journal of Arts Medicine 1995; 4(1): 24-31.

30 Pratt RR. Fund raising and research. In: Pratt RR, editor. Hospital arts. St. Louis (MO): MMB Music; 1997; P.26-31.

31 Pratt RR. Listening to music during surgery: a program of Intermountain Health. Interview with Marian North, RN, and Don Woodbury, Dir. Mktg. \& Res. IHC. International Journal of Arts Medicine 1999; 6(1): 21-30. 


\section{INTERNATIONAL JOURNAL Of RESEARCH -GRANTHAALAYAH

32 Presner JD. Yowler CJ, Smith LF, Steele AL, Fratianne RB. Music therapy for assistance with pain and anxiety management in burn treatment. Journal of Burn Care 2001; 22(1): 83-8.

33 Pennebaker, J.W. Opening up: The healing power of expressing emotions. New York: Guilford Press; 1997

34 Reinemann D. ROM dance: a treatment for symptoms of depression and anxiety in adults with mental retardation. Dissertation Abstracts International: Section B: The Sciences and Engineering. 1999; 60(3-B): 1051.

35 Ritter M. Low KG. Effects of dance/movement therapy: a meta-analysis. Arts in Psychotherapy 1996; 23(3): 249-60.

36 Robbins A. Dance/movement and art therapies as primary expressions of the self. In: Robbins A, editor. Therapeutic presence: bridging expressions and form. Bristol (PA): Jessica Kingsley; 1998; p,261-70.

37 Rosenfeld JV, Dun B. Music therapy in children with severe traumatic brain injury in: Pratt RR, Grocke DE, editors. Music Medicine 3. Melbourne (Australia): University of Australia; 1999. P.35-46.

38 Schmais AN. Dance therapy in perspective. In: perspective. In: Mason KC, editor. Dance therapy: focus on dance. Washington, DC: American Alliance for Health, Physical Education, and Recreation; 1980; $p$ 7-12.

39 Schneider EH, Unkefer RF, Gaston ET. Introduction. In: Gaston ET, editor. Music in therapy. New York: Macmillan; 1968; p.2-4.

40 Scott AH, Butin DN, Tewfik D, Hiller A, Danielle N. Occupational therapy as a means to wellness with the elderly. Phys Occup Ther Geriatr 2001;18(4):3-22.

41 Sedei Godley CA. The use of music therapy in pain clinics. Music Ther Persp 1987; 4:248.

42 Shertzer KE, Keck JF. Music and the PACU environment. J Perianesth Nurs 2001; 16(2):90-120.

43 Tanabe P. Perket K, Thomas R, Paice J, Marcantonio R. The effects of standard care, ibuprofen, and distraction on pain relief and patient satisfaction in children with musculoskeletal trauma. J Emerg Nurs 2002; 28(2):118-25.

44 Truppi AM. The effects of dance/movement therapy on sexually abused adolescent girls in residential treatment. Dissertations Abstracts International: Section B: The Science and Engineering. 2001; 62(4-B) [US: University Microfilms International].

45 Valentine-Garzon MA, Maynard M. Selznick SZ. Dance program effects on frail women in an adult day care center. Phys Occup Ther Geriatr 1992; 11(1):63-83. 